\title{
High flow nasal cannula vs non-invasive ventilation in pediatric ARDS: an RCT
}

\author{
Chandra S. ${ }^{1}$, Vijayshri ${ }^{2}$, Gupta A. ${ }^{3}$, Goyal P. ${ }^{4}$, Prasad P.L. ${ }^{5}$ \\ ${ }^{1}$ Dr. Surabhi Chandra, Assistant Professor, ${ }^{2}$ Dr. Vijayshri, Junior Resident, IIIrd year, ${ }^{3}$ Dr. Aditi Gupta, Junior Resident, \\ IIIrd year, ${ }^{4}$ Dr. Pratishtha Goyal, Junior Resident, IIIrd year, ${ }^{5}$ Dr. P. L. Prasad, Professor \& Head of Department, all \\ authors are attached with Department of Pediatrics, SRMS Institute of Medical Sciences, Bareilly, UP, India.
}

Corresponding Author: Dr. Surabhi Chandra, Assistant Professor, Department of Pediatrics, SRMS-IMS, Bhojipura, Bareilly. Email id: surabhi0329@gmail.com

\begin{abstract}
Introduction: Pediatric Acute Respiratory Distress syndrome (PARDS) has been re-defined (2015) as per the final recommendations of the Pediatric Acute Lung Injury Consensus Conference. The use of high flow nasal cannula is a promising treatment but its efficacy compared with non invasive ventilation (NIV) is not known. Aims and Objectives: The current study was undertaken to study the efficacy of high flow nasal cannula compared with NIV in PARDS. Methods: This was a pilot randomized controlled trial done in the PICU of a tertiary care teaching hospital over 10 months (December 2017 - September 2018). All patients aged 1-18 years of age, who presented with or developed ARDS during their course of hospitalization, and who fulfilled the inclusion criteria, were randomized to receive HFNC and Continuous Positive Airway Pressure (NIV) as the initial respiratory support. Details were noted in a pre-designed standardized data collection form, entered into MS-EXCEL worksheet 2013 and analyzed using the Epi info software version 7.2.0.1. Results: A total of 40 patients were enrolled, 20 in each arm.Of these majority $(25 / 40=62.5 \%)$ were boys. Majority of these patients were from rural or semi-urban areas $(28 / 40=70.0 \%)$ and belonged to low socio-economic class $(33 / 40=82.5 \%)$ patients.Underlying diagnosis was sepsis in the majority $(27 / 40=67.5 \%)$ patients. Twenty one $(23 / 40=57.5 \%)$ patients had co-existent pneumonia. Development of hemodynamic instability approached statistical significance in being low in HFNC group compared with the CPAP group ( $\mathrm{p}=0.07$; OR 0.206, 95\% CI 0.036-0.159). Subsequent requirement of invasive ventilation was also low in HFNC group compared with CPAP group and approached significance ( $\mathrm{p}=0.09$; OR 1.653 , 95\% CI 0.074-1.246). Total duration of respiratory support ( $\mathrm{p}=0.62)$ was comparable in both the groups. Conclusion: HFNC is efficacious in managing PARDS. Subsequent requirement of invasive ventilation and hemodynamic deterioration was significantly low with HFNC compared with NIV (CPAP).
\end{abstract}

Keywords: HFNC, Pediatric ARDS, Non invasive ventilation

\section{Introduction}

Acute Respiratory Distress syndrome (ARDS) is characterized by hypoxemia, dyspnea and a marked increase in work of breathing [1]. It has been re-defined (2015), in children, as per the final recommendations of the Pediatric Acute Lung Injury Consensus Conference (PALICC) [2]. Prevalence of PARDS (Pediatric acute respiratory Distress Syndrome) as it is now known as, has been found to be upto $9.9 \%$ in a recent study [3]. The use of high flow nasal cannula is a promising treatment but its efficacy compared with non invasive ventilation (NIV) in management of PARDS or acute hypoxemic respiratory failure [4] is not known $[5,6]$.

Manuscript received: $8^{\text {th }}$ November 2018

Reviewed: $18^{\text {th }}$ November 2018

Author Corrected: $24^{\text {th }}$ November 2018

Accepted for Publication: $28^{\text {th }}$ November 2018

\section{Aims and Objectives}

The current study was undertaken to compareoxygen therapy by high flow nasal cannula vs Noninvasive positive pressure ventilation (Continuous Positive Airway Pressure) in management of PARDS in terms of;

1. Development of hemodynamic instability.

2. Subsequent requirement of invasive ventilation.

3 . Total duration of respiratory support.

\section{Patients and Methods}

Study type, place and duration- It was a prospective observational study done in the PICU of a tertiary care 
Letter to Editor

teaching hospital, over 10 months (December 2017 September 2018), after obtaining ethical clearance from the Institutional Ethics Committee. PARDS was defined as per the standard definition given by Pediatric Acute Lung Injury Consensus Conference [2].

Sample collection, Inclusion and Exclusion criteriaAll patients aged 1-18 years, who presented with or developed ARDS during their course of hospitalization, were included, after taking a written informed consent from their parents/guardians. Patients with PARDS requiring intubation directly, those with chronic cardiorespiratory disease, any congenital cardio-respiratory condition, cyanotic congenital heart disease or with negative parental consent were excluded. Patients were randomized to receive either CPAP (NIV) or oxygen therapy via HFNC as the initial respiratory support.

Statistical methods- Demographic, clinical, laboratory and management details were recorded on a predesigned standardized data collection form. Data was later entered into MS-EXCEL worksheet 2013 and analyzed using the Epi info software version 7.2.0.1. Frequencies were calculated for categorical data and means for continuous variables. $\mathrm{P}$ value of $<0.05$ was considered to be statistically significant.

\section{Results}

There were 324 admissions to the PICU during the study period. Of these, a total of $51(15.7 \%)$ patients presented (41/51 $=80.3 \%)$ with or developed ARDS $(10 / 51=19.6 \%)$ during the course of their hospitalization. Of these, 8 patients required intubation directly, 2 patients gave negative consent and one patient went on leave against medical advice. Hence 40 patients were enrolled, 20 in each arm.

Of these majority $(25 / 40=62.5 \%)$ were boys. Majority of these patients were from rural or semi-urban areas $(28 / 40=70.0 \%)$ and belonged to low socio-economic class $(33 / 40=82.5 \%)$ patients. Mean age of presentation was 12.9 years (Range 8-16 years; SD 2.169).

Underlying diagnosis was sepsis in the majority $(27 / 40=67.5 \%)$ patients. Twenty one $(23 / 40=57.5 \%)$ patients had coexistent pneumonia. Other diagnoses were severe malaria $(4 / 40=10.0 \%)$, gastric aspiration $(3 / 40=7.5 \%)$, hydrocarbon poisoning $(3 / 40=7.5 \%)$, near drowning $(1 / 40=2.5 \%)$ acute pancreatitis $(1 / 40=2.5 \%)$ and burn inhalational injury $(1 / 40=2.5 \%)$.

Mean P:F (PaO2:FiO2) ratio was 237.7 (Range 180-290; SD 33.02). Hypotension developed or worsened in 2 patients in the HFNC group and 7 in the CPAP group. All patients with hemodynamic deterioration were managed with invasive mechanical ventilation. Subsequent requirement of invasive ventilation was required in 4 patients in the HFNC group compared with 9 patients in the CPAP group.

Mean duration of respiratory support was 74 hours (Range 36-120 hours; SD 23.7) in the HFNC group and 77.8 hours (Range 36-120 hours; SD 24.6) in the CPAP group.

Development of hemodynamic instability approached statistical significance in being low in HFNC group compared with the CPAP group ( $\mathrm{p}=0.07$; OR $0.206,95 \%$ CI 0.036-0.159). Subsequent requirement of invasive ventilation was also low in HFNC group compared with CPAP group and approached significance $(\mathrm{p}=0.09$; OR 1.653, 95\% CI 0.074-1.246). Total duration of respiratory support $(\mathrm{p}=0.62)$ was comparable in both the groups.

Table 1: Comparison of HFNC \& CPAP group.

\begin{tabular}{|c|c|c|c|c|c|}
\hline S No & Parameter & $\begin{array}{c}\text { CPAP Group } \\
\mathbf{n = 2 0}\end{array}$ & $\begin{array}{c}\text { HFNC Group } \\
\mathbf{n = 2 0}\end{array}$ & $\begin{array}{c}\text { OR } \\
\mathbf{( 9 5 \%} \mathbf{~ C I})\end{array}$ & P value \\
\hline 1. & $\begin{array}{c}\text { Development of } \\
\text { hemodynamic instability }\end{array}$ & 7 & 2 & 0.206 & 0.07 \\
\hline 2. & $\begin{array}{c}\text { Subsequent requirement of } \\
\text { invasive ventilation }\end{array}$ & 9 & 4 & 1.653 & 0.09 \\
\hline 3. & $\begin{array}{c}\text { Total duration of } \\
\text { respiratory support } \\
\text { (in hours) }\end{array}$ & $77.8(36-120)$ & $74(36-120)$ & & 0.62 \\
\hline
\end{tabular}




\section{Discussion}

High Flow Nasal Cannula oxygen therapy is effective in management of pediatric ARDS, when compared with Non-Invasive Ventilation (CPAP).

ARDS was seen in this study was found to be $15.07 \%$ of the 324 patients admitted to the PICU, during the study period.

A prevalence of $9.9 \%$ was found in another study [3], which enrolled patients fulfilling the PARDS criteria defined by the PALICC [2].

Underlying etiology of ARDS was sepsis in majority $(67.5 \%)$ of the pediatric patients in our study, of whom $57.5 \%$ patients had co-existent pneumonia. In another study, done in adult patients, pneumonia accounted for the majority (82\%) of cases of ARDS [7].

A recent study of 75 patients, $>13$ years of age, from an urban tropical setting in India, found that Leptospirosis was the most common (18.7\%) underlying etiology, and concluded that tropical infections are the major etiological component of ARDS in a developing country like India [8].

Therapeutic effect of HFNC oxygen therapy was evaluated in treating an adult patient of Middle East Respiratory syndrome (MERS) in whom respiratory function improved and the complication of ARDS was prevented [9].

Another single centre observational study in adult patients (mean age 57.9 years), concluded that HFNC may be considered as first-line therapy in acute respiratory failure, including patients with ARDS [7].

To the best of our knowledge, there has been no trial to compare the efficacy of high flow nasal cannula oxygen therapy with non invasive ventilation in ARDS per se in children.

However, an observational study comparing the efficacy of sequential application of oxygen therapy via HFNC and NIV, found that HFNC was better tolerated than NIV and allowed for significant improvement in oxygenation and tachypnea compared with standard oxygen therapy in subjects with AHRF (Acute Hypoxemic Respiratory Failure), and advocated the use of HFNC in between the NIV sessions [10].

Mean P:F ratio was 237.7 in our study. A low mean P:F score between 200-300 (which was earlier classified as
"Mild" ARDS in children, as per the Berlin definition [11]) might be one of the possible reasons why HFNC proved to be efficacious in management of ARDS, in this study.

Even NIV application is to be limited only to mild forms of ARDS, as its use is associated with higher rates of treatment failure and mortality in severe forms [12].

The study was limited in not comparing the final outcome or survival to discharge in both the groups, as this was not the primary objective. Also, results are approaching statistical significance and are not clearly significant, which might be attributed in part to small number of patients in both the groups.

Hence more robust studies are required to prove efficacy of HFNC over NIV in ARDS in future. Similar conclusion was drawn by Wolfler A et al [5], who evaluated the use of HFNC and NIV in infants with severe bronchiolitis.

\section{Conclusion}

HFNC is efficacious in managing PARDS. Subsequent requirement of invasive ventilation and hemodynamic deterioration was significantly low with HFNC compared with NIV (CPAP).

\section{What this study adds?}

This study proves that high flow nasal cannula oxygen therapy is better than non invasive ventilation, in managing patients with PARDS.

\section{Author contribution}

- Surabhi Chandra - Conceived the idea, devised methodology and prepared the manuscript

- Vijayshri, Aditi Gupta, Pratishtha Goyal - Helped in data collection and manuscript preparation

- PL Prasad - Supervision and critical analysis

Funding: Nil, Conflict of interest: None initiated, Perission from IRB: Yes

\section{References}

1. Jinfeng Liu, Wei Wang. Fengli Liu, Zhenguang Li. Pediatric acute respiratory distress syndrome - current views (Review) December 14, 2017 https//doi.org/10. 3892/ etm.2017.5628 


\section{Letter to Editor}

2. Pediatric Acute Lung Injury Consensus Conference Group. Pediatric acute respiratory distress syndrome: consensus recommendations from the Pediatric Acute Lung Injury Consensus Conference. Pediatr Crit Care Med. 2015 Jun;16 (5): 428-39. doi: 10.1097/PCC.000 0000000000350 .

3. Gupta S, Sankar J, Lodha R, et al. Comparison of Prevalence and Outcomes of Pediatric Acute Respiratory Distress Syndrome Using Pediatric Acute Lung Injury Consensus Conference Criteria and Berlin Definition. Front Pediatr. 2018 Apr 9;6:93. doi: 10.3389 /fped. 2018.00093. eCollection 2018.

4. Grassi A, Foti G, Laffey JG, et al. Noninvasive mechanical ventilation in early acute respiratory distress syndrome. Pol Arch Intern Med. 2017 Sep 29; 127(9): 614-620. doi:10.20452/pamw.4088. Epub 2017 Aug 17.

5. Wolfler A, Raimondi G, Pagan de Paganis C, Zoia E. The infant with severe bronchiolitis: from HFNC to CPAP and mechanical ventilation. Minerva Pediatr. 2018 Oct 18. doi: 10.23736/S0026-4946.18.05358-6. [Epub ahead of print]

6. Randolph AG. Management of acute lung injury and acute respiratory distress syndrome in children. Crit Care Med. 2009 Aug;37(8):2448-54. doi: 10.1097/ CCM. 0b013e3181aee5dd.

7. Messika J, Ben Ahmed K, Gaudry S, et al. Use of High-Flow Nasal Cannula Oxygen Therapy in Subjects With ARDS: A 1-Year Observational Study. Respir
Care. 2015 Feb; 60(2):162-9. doi: 10.4187/respcare. 03423. Epub 2014 Nov 4.

8. Kumar SS, SelvarajanChettiar KP, Nambiar R. et al. Etiology and Outcomes of ARDS in a Resource Limited Urban Tropical Setting. J Natl Med Assoc. 2018 Aug; 110(4):352-357. doi: 10.1016/j.jnma.2017.07.002. Epub 2017 Jul 18.

9. Luo Y, Ou R, Ling Y, et al. [The therapeutic effect of high flow nasal cannula oxygen therapy for the first imported case of Middle East respiratory syndrome to China]. Zhonghua Wei Zhong Bing Ji Jiu Yi Xue. 2015 Oct;27(10):841-4.

10. Frat JP, Brugiere B, Ragot S, et al. Sequential application of oxygen therapy via high-flow nasal cannula and noninvasive ventilation in acute respiratory failure: an observational pilot study. Respir Care. 2015 Feb; 60 (2): 170-8. doi: 10. 4187/respcare. 03075. Epub 2014 Oct 7.

11.Vito Fanelli, AikateriniVlachou, Shirin Ghannadian, Umberto Simonetti, Arthur S. Slutsky, and Haibo Zhang. Acute respiratory distress syndrome: new definition, current and future therapeutic options. J Thorac Dis. 2013 Jun; 5(3): 326-334. doi: [10.3978/j. issn. 2072-1439.2013.04.05]

12. Westhoff M, Schönhofer B, Neumann P, et al. Noninvasive Mechanical Ventilation in Acute Respiratory Failure. Pneumologie. 2015 Dec; 69(12): 719-756. doi: 10.1055/s-0034-1393309. Epub 2015 Dec 9.DOI:

\section{How to cite this article?}

Chandra S, Vijayshri, Gupta A, Goyal P, Prasad P.L. High flow nasal cannula vs non-invasive ventilation in pediatric ARDS: an RCT. Int J Pediatr Res. 2018;5(11):592-595.doi:10.17511/ijpr.2018.i11.07. 